\title{
The $1962 \mathrm{He}^{3}$ Scale of Temperatures III. Evaluation and Status ${ }^{2}$
}

\author{
T. R. Roberts, R. H. Sherman, and S. G. Sydoriak \\ Los Alamos Scientific Laboratory, University of California \\ Los Alamos, N. Mex.
}

(June 16, 1964)

\begin{abstract}
In this third paper the $1962 \mathrm{He}^{3}$ Scale of Temperatures is evaluated both as to its precision and its deviations from the thermodynamic Kelvin Scale. Various thermodynamic quantities of $\mathrm{He}^{3}$ consistent with the $1962 \mathrm{He}^{3}$ Scale are derived and listed. The correction to an observed vapor pressure for small amounts of $\mathrm{He}^{4}$ is discussed and tabulated. A description is given of the method of multiple variable least squares analysis used for deriving the final scale equation and for re-analysis of isotherm data. Finally the present status of the $1962 \mathrm{He}^{3}$ Scale is discussed along with some considerations for the future.
\end{abstract}

\section{An Evaluation of the $1962 \mathrm{He}^{3}$ Scale \\ 1.1. Fit of the Input 1961 L.A.S.L. Vapor-Pressure Data}

One factor in evaluating the $1962 \mathrm{He}^{3}$ Scale is the fit of the input vapor-pressure data of Part I [46] to the Scale. Figure 1 and table 1 of Part II [6] show the deviations of the observed data from the final scale as $\mathrm{T}_{62}\left(P_{3}\right)-T_{58}\left(P_{4}\right)$. The symbol $T_{62}$ is the temperature on the $1962 \mathrm{He}^{3}$ Scale corresponding to a $\mathrm{He}^{3}$ vapor pressure, $P_{3}$, while $T_{58}$ is the temperature on the $1958 \mathrm{He}^{4}$ Scale [2] corresponding to the experimentally determined isothermal $\mathrm{He}^{4}$ vapor pressure, $P_{4}$. The standard deviation of the data from the scale is $0.25 \mathrm{mdeg}$ and the maximum deviation over the full range is 0.6 mdeg. The data may not scatter completely randomly. For example, the data points just below $2{ }^{\circ} \mathrm{K}$ are all below the 1958 $\mathrm{He}^{4}$ Scale and the points just above $2^{\circ} \mathrm{K}$ are all above the $1958 \mathrm{He}^{4}$ Scale. Hence, if one wished to obtain the vapor pressure of $\mathrm{He}^{3}$ which is most probably isothermal with a given $\mathrm{He}^{4}$ vapor pressure, a slightly better value (in terms of consistency with the observed data) may be obtained by drawing a smooth curve through these data points or by using direct interpolation equations as discussed in Part I. However, the overall fit of the Scale to the input data is very satisfactory in comparison with the errors of measurement of the two vapor pressures. 1. Much of the material in this paper III has been included in a review chapter
[52] on the development of the scale.

2 Work performed under the auspices of the U.S. Atomic Energy Commission.
1.2. Fit of the Experimental Thermodynamic Equation (ETE) Scale

Below $0.9^{\circ} \mathrm{K}$ the $1962 \mathrm{He}^{3}$ Scale was evaluated by examining its fit to the ETE Scale described in Part II. The ETE Scale is defined by a linear equation fitted to an empirical function, $F_{x}\left(P_{3}, T\right)$, of $\mathrm{He}^{3}$ vapor pressure and temperature,

$$
F_{x}\left(P_{3}, T\right)=(a+b T) / R .
$$

As shown by the full line curve in figure 1 of Part II temperatures calculated from eq (1) are in good agreement with the $1962 \mathrm{He}^{3}$ Scale; nowhere below $2{ }^{\circ} \mathrm{K}$ do the scales differ by more than 0.4 mdeg. the $1962 \mathrm{He}^{3}$ Scale, defined by eq (9b) of Part II, is therefore in effect an E'TE scale from 0.2 to $2^{\circ}$ and an empirical scale above $2^{\circ} \mathrm{K}$.

The effect of possible errors in the various terms of the equation for the ETE scale, over the temperature range from 0.2 to $1.0^{\circ} \mathrm{K}$, should also be considered in evaluating the $1962 \mathrm{He}^{3}$ Scale. The ETE scale was obtained from a least squares fit of the $\mathrm{He}^{3}-\mathrm{He}^{4}$ vapor-pressure intercomparisons between 0.9 and $2.0^{\circ} \mathrm{K}$ to eq (1). The function $F_{x}\left(P_{3}, T\right)$ is calculated for each experimental $P_{3}, T_{58}$-observation; deviations of this "observed" value of $F_{x}\left(P_{3}, T\right)$ from the fitted value, $\left[\left(a+b T_{58}\right) / R\right]$, from eq (1) are shown as circles in figure 1 . The function $F_{x}\left(P_{3}, T\right)$ is derived in Part II and in ref. [10] as

$$
\begin{aligned}
F_{x}\left(P_{3}, T\right)=T[(5 / 2) \ln T- & \ln P_{3}+i_{0} \\
& \left.+f_{x}\left(V_{L}\right)-f_{x}\left(C_{s a t}\right)+\epsilon\right]
\end{aligned}
$$




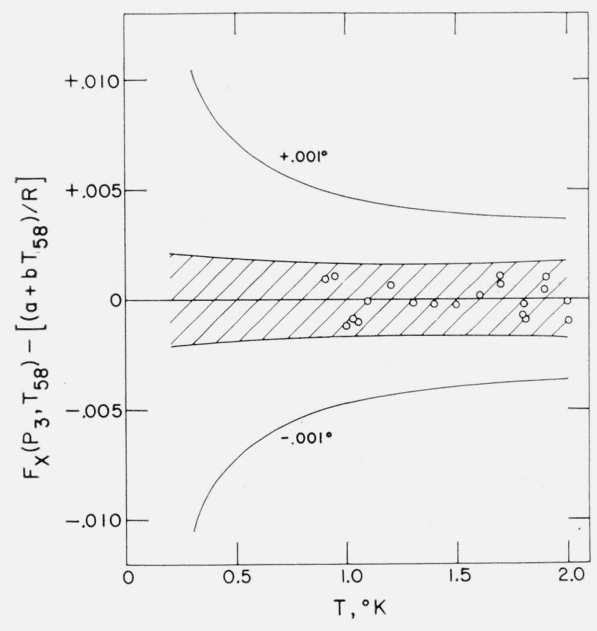

Figure 1.-Deviations from the ETE Scale, eq (1).

The circles are deviations from the fitted equation of the function $F_{x}\left(P_{3}, T_{58}\right)$ calculated from eq (2) for each input $\left(P_{3}, T_{58}\right)$ data point. The central crosshatched area is the 95 percent prediction interval [53] for a prediction of $F_{x}\left(P_{3}, T\right)$ from eq (1) as calculated from the \pm values for $a$ and $b$ given in eqs (3) and (4) The outermost solid curves represent a change in $F_{x}\left(P_{3}, T\right)$ corresponding to a 1 mdeg change in temperature and are calculated as $0.001 T\left(d \ln P_{3} / d T\right)_{\text {sat }}$.

where $i_{0}$ is the chemical constant including the nuclear spin degeneracy; $f_{x}\left(V_{L}\right)$ is an empirical power series representing the theoretical and exact integral term,

$$
f\left(V_{L}\right) \equiv(1 / R T) \int_{0}^{T} V_{L}\left(d P_{3} / d T\right)_{\mathrm{sat}} d T
$$

involving the molar liquid volume, $V_{L} ; f_{x}\left(C_{\text {sat }}\right)$ is an equation for the theoretical and exact double integral term of eq (3a) of Part II, $f\left(C_{\mathrm{sat}}\right) \equiv(1 / R T) \int_{1}^{T^{\prime}} d T^{\prime}$ $\int_{1}^{T^{\prime}}\left(C_{\mathrm{sat}} / T^{\prime \prime}\right) d T^{\prime \prime}$, based on an empirical power series fitted between 0.2 and $2.0{ }^{\circ} \mathrm{K}$ to data for $C_{\text {sat }}$, the specific heat of the saturated liquid; and $\epsilon$ is the gas imperfection term, eq (4a) of Part II.

The least squares values for the coefficients $a$ and $b$ of eq (1), and their equivalent expressions from eqs (6) and (7) of Part II are

$a=L_{0}-\int_{0}^{1} C_{\text {sat }} d T=17.4459 \pm 0.0058$ joule mole $^{-1}$

and

$b=S_{L}\left(1.0^{\circ}\right)=9.0098 \pm 0.0038$ joule mole ${ }^{-1} \mathrm{deg}^{-1}$.

The plus-or-minus values for $a$ and $b$ were found from the fit of the data points to the straight line, $a+b T$. Mood [53] has given an equation for the prediction interval for a single prediction of $F_{x}\left(P_{3}, T\right)$ from eq (1) for any value of $T$. The ETE Scale is just the set of $\mathrm{P}_{3}$ values obtained by solving eq (2) for $\ln P_{3}$ at any given temperature using the predicted value of $F_{x}\left(P_{3}, T\right)$. Hence a prediction interval for $F_{x}\left(P_{3}, T\right)$ can be expressed as an equiva- lent prediction interval in $P_{3}$ by neglecting the contribution of possible errors in the other terms on the right hand side of eq (2).

The 95 percent prediction interval for a single prediction of $F_{x}\left(P_{3}, T\right)$ [with a 95 percent probability of containing the statistically "true" value of $\left.F_{x}\left(P_{3}, T\right)\right]$ is shown as the central cross-hatched area in figure 1 . The outermost curves in this figure show the change in $F_{x}^{*}\left(P_{3}, \mathrm{~T}\right)$ corresponding to a one millidegree change in temperature. The same prediction intervals have been converted to equivalent temperature scale errors as listed in table 1.

The effects of random errors of \pm 3 percent in $f_{x}\left(C_{\mathrm{sat}}\right)$ and $\epsilon$ on individual temperatures below $1^{\circ}$ are also shown in table 1.

Systematic errors in $f_{x}\left(C_{\text {sat }}\right), \epsilon$ and in $f_{x}\left(V_{L}\right)$ would be compensated between $0.9^{\circ}$ and $2.0^{\circ}$ by the least squares process of fitting the $\left(P_{3}, T_{58}\right)$ data to eq (1). The scale below $1^{\circ}$ would be skewed by such errors as is shown in table 1 for assumed 3 percent systematic errors in all values of $C_{\text {sat }}$ or $\epsilon$. Table 1 also shows the systematic errors below $1^{\circ}$ resulting from use of the approximate empirical function, $f_{x}\left(V_{L}\right)$, instead of the graphically integrated values of the true thermodynamic function, $f\left(V_{L}\right)$ [see table 4 of Part II].

Another possible source of systematic error is a smooth deviation of the $1958 \mathrm{He}^{4}$ Scale from the thermodynamic Kelvin Scale. The effect on the ETE scale of adding 2 mdeg to each scale input temperature is listed in table 1 .

TABLE 1. Effect of possible systematic or random errors on the ETE scale, eq (1)

Systematic or random changes in the constants $a$ and $b$ of eqs (3) and (4) and of temperatures on the ETE scale below $1^{\circ} \mathrm{K}$ are listed for the following arbitrary, but plausible, cases:

Case 1. the fit of the input $\left(P_{3}, T_{58}\right)$ data expressed as the 95 percent confidence limit [53] for the prediction of a value of $\ln P$ at any single temperature (see fig. 1);

Case 2. random errors of \pm 3 percent in $f_{x}\left(C_{\text {sat }}\right)$;

Case 3 . random errors of \pm 3 percent in $\epsilon$, eq (4a) of Part II;

Case 4. a systematic error of -3 percent in all $C_{\text {sat }}$ values, and hence in $f_{x}\left(C_{\text {sat }}\right)$ Case 5. a systematic error of +3 percent in all values of $\epsilon$

Case 6 , the difference between the empirical function, $f_{x}\left(V_{L}\right)$, and the numerically integrated values of the thermodynamic term, $f\left(V_{L}\right)=\int_{0}^{T} V_{L}(d P / d T)_{\text {sat }}$ $d T$; and

Case 7 . the increase of all values of input temperatures between 0.9 and $2.0^{\circ} \mathrm{K}$ by adding 0.002 deg to each $T_{58}$.

\begin{tabular}{|c|c|c|c|c|c|c|c|}
\hline \multirow{2}{*}{ Case } & \multirow{2}{*}{$\Delta a$} & \multirow{2}{*}{$\Delta b$} & \multicolumn{5}{|c|}{$\Delta T$} \\
\hline & & & $1.0^{\circ} \mathrm{K}$ & $0.8^{\circ} \mathrm{K}$ & $0.6^{\circ} \mathrm{K}$ & $0.4^{\circ} \mathrm{K}$ & $0.2^{\circ} \mathrm{K}$ \\
\hline $\begin{array}{l}1 \\
2 \\
3 \\
4 \\
6 \\
6 \\
7\end{array}$ & $\begin{array}{r}\begin{array}{r}J \\
1 \text { mole } \\
\pm 0.006\end{array} \\
0.069 \\
0.073 \\
0.094\end{array}$ & $\begin{array}{c}J / \text { mole deg } \\
\pm 0.004\end{array}$ & $\begin{array}{r}\text { mdeg } \\
\pm 0.4 \\
0.0 \\
\pm 0.2 \\
0.2 \\
0.2 \\
-0.1\end{array}$ & $\begin{array}{l}\text { mdeg } \\
\pm 0.3 \\
\pm 0.1 \\
\pm 0.1 \\
0.5 \\
0.4 \\
-0.1 \\
1.7\end{array}$ & $\begin{array}{r}\text { mdeg } \\
\pm 0.3 \\
\pm 0.2 \\
0.0 \\
0.8 \\
0.5 \\
-0.1 \\
1.5\end{array}$ & $\begin{array}{r}\text { mdeg } \\
\pm 0.2 \\
\pm 0.4 \\
0.0 \\
1.0 \\
0.6 \\
0.0 \\
1.2\end{array}$ & $\begin{array}{r}m d e g \\
\pm 0.1 \\
\pm 0.4 \\
0.0 \\
1.0 \\
0.5 \\
0.0 \\
0.7\end{array}$ \\
\hline
\end{tabular}

The overall effect on the $1962 \mathrm{He}^{3}$ Scale of random errors in the specific heat of liquid $\mathrm{He}^{3}$, the virial coefficient equations, and the $1958 \mathrm{He}^{4}$ Scale might amount to as much as three millidegrees. Durieux [54] has analyzed the $1962 \mathrm{He}^{3}$ Scale for the effects of possible errors and has reached similar conclusions. 


\subsection{Fit of the Argonne Laboratory Vapor-Pressure Data}

The $\mathrm{He}^{3}-\mathrm{He}^{4}$ vapor-pressure intercomparisons of Abraham, Osborne, and Weinstock [5] have been used in deriving all previous $\mathrm{He}^{3}$ temperature scales, but these were rejected for the $1962 \mathrm{He}^{3}$ Scale because of apparent thermodynamic inconsistency (see refs. [10 and 45]) with recent precise measurements of the latent heat of vaporization of $\mathrm{He}^{3}$ by the same workers $[4,55]$. The fit of the $\mathrm{AOW}$ vapor-pressure data to the $1962 \mathrm{He}^{3}$ Scale is shown in figure 2. Above $1.9^{\circ}$ the agreement is within 0.5 mdeg. Below $1.5^{\circ}$ the $\mathrm{AOW}$ data deviate systematically from the 1962 Scale indicating either that their $\mathrm{He}^{3}$ vapor pressures were lower or that their $\mathrm{He}^{4}$ pressures were higher than the data of Sydoriak and Sherman (Part I). For encircled points in figure 2, a $\mathrm{He}^{4}$ vapor pressure bulb was fastened to the $\mathrm{He}^{3}$ bulb. The $\mathrm{He}^{4}$ pressure may have been high because of insufficient correction for effects due to the refluxing superfluid film. For the uncircled crosses and dots, the $\mathrm{He}^{4}$ bath pressure was measured in the pumping line in a warm part of the apparatus. The corrected $\mathrm{He}^{4}$ pressures as published may have been high because the effluent gas was significantly colder than the tip of the pressure-sensing tube, thus increasing the actual thermomolecular pressure difference.

\subsection{Fit of Heat-of-Vaporization Data}

Heat-of-vaporization, $L$, data may be used to test the thermodynamic consistency of the temperature scale. The equations used may be either

$$
L=T\left(S_{G}-S_{L}\right)
$$

with the vapor entropy, $S_{G}$, calculated from the Sackur-Tetrode equation, or

$$
L=T\left(V_{G}-V_{L}\right)(d P / d T)_{\mathrm{sat}}
$$

from the Clausius-Clapeyron equation. The use of these equations for testing $\mathrm{He}^{4}$ scales of temperature has been discussed extensively; see van Dijk and Durieux [25], Durieux [15], Berman and Mate [56], and Keller [43].

The liquid entropy at $1.0{ }^{\circ} \mathrm{K}$ (or any other temperature) may be calculated from eq (5) and data for $C_{\text {sat }}$ as

$$
S_{L}\left(1.0^{\circ}\right)=S_{G}(T)-(L / T)-\int_{1 \cdot 0}^{T}\left(C_{\text {sat }} / T^{\prime}\right) d T^{\prime} .
$$

The Argonne (WAO) heat-of-vaporization measurements [4] were undertaken in order to determine the entropy of liquid $\mathrm{He}^{3}$ in this way.

At one stage of the derivation of the $1962 \mathrm{He}^{3}$ Scale, it was proposed [10] to use all the WAO heat-of-vaporization data and eq (7) to get an average value for $S_{L}\left(1.0^{\circ}\right)$, which is just the coefficient, $b$, in eqs (1) and (4). Then, values of $(a / R)=$
$F_{x}\left(P_{3}, T\right)-(b T / R)$ from eq (1) were computed for every vapor-pressure datum point between 0.9 and $2.0^{\circ} \mathrm{K}$. This two-step method failed to converge on a stable, consistent pair of constants $a$ and $b$, and led to the decision to undertake the new L.A.S.L. intercomparisons of the vapor pressures of $\mathrm{He}^{3}$ and $\mathrm{He}^{4}$. Analysis of the new intercomparisons [45] by this same two-step method also failed to yield a consistent set of $a$ and $b$ values, although these data showed much less scatter, as shown in figure 3. The heat-of-vaporization data were not used to determine the $1962 \mathrm{He}^{3}$ Scale; instead $a$ and $b$ values were obtained by a least squares fit of the $\mathrm{He}^{3}$ vapor-pressure data to eq (1) using for $T$ the $T_{58}$

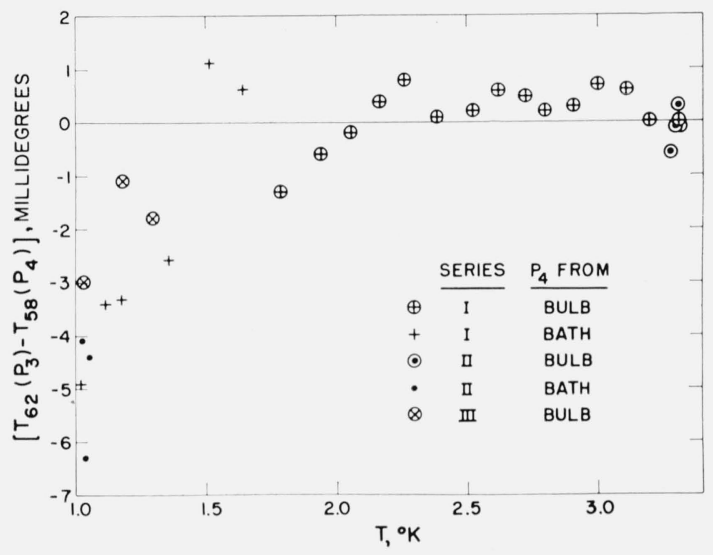

Figure 2.-The deviation in millidegrees of the 1950 Abraham, Osborne, and Weinstock [5] $\left(\mathrm{P}_{3}, \mathrm{P}_{4}\right)$ data from the $1962 \mathrm{He}^{3}$ Scale: $\mathrm{T}_{62}\left(\mathrm{P}_{3}\right)-\mathrm{T}_{58}\left(\mathrm{P}_{4}\right)$.

The uncircled crosses and small dots are data points below the $\lambda$-point for which the $\mathrm{He}^{4}$ cryostat bath pressure was published as $P_{4}$. For the encircled points a $\mathrm{He}^{4}$ vapor pressure bulb was fastened to the $\mathrm{He}^{3}$ bulb.

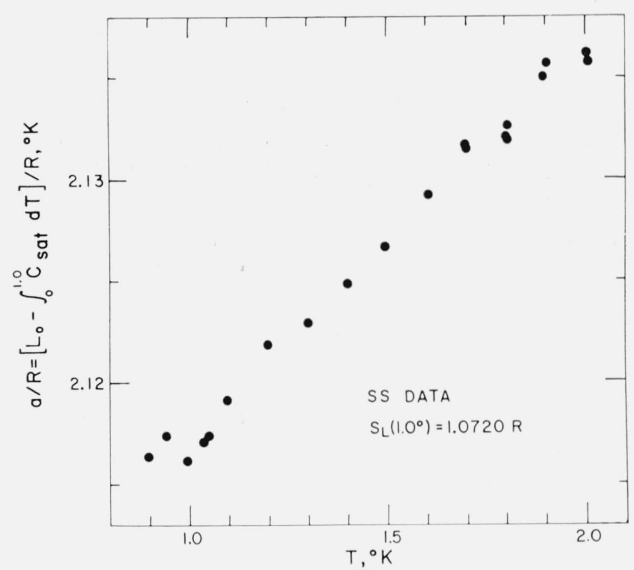

FiguRE 3.-Demonstration of the remaining thermodynamic inconsistency between eqs (1) and (7) involving the $\mathrm{He}^{3}$ latentheat data, $\left(L, P_{3}\right)$, of Weinstock, Abraham, and Osborne [4], [55]; the $\left(\mathrm{P}_{3}, \mathrm{P}_{4}\right)$ intercomparisons of Sydoriak and Sherman [46]; and the $1958 \mathrm{He}^{4}$ Scale [2], $\mathrm{T}_{58}\left(\mathrm{P}_{4}\right)$.

The indicated value of $S_{L}\left(1.0^{\circ}\right)$ is the average of nine values calculated from eq (7) for the WAO $\left(L, P_{3}\right)$ data and is about 1 percent lower than the $1962 \mathrm{He}^{3}$ Scale value for that entropy, eq (4). The solid circles are the individual values of the theoretical constant, $(a / R)$, in eq (1) calculated for each $\left(P_{3}, T_{58}\right)$ data point Ias $F_{x}\left(P_{3}, T_{58}\right)-\left[S_{L}\left(1.0^{\circ}\right) T_{58} / R\right]$ using the indicated a verage value of $S_{L}\left(1.0^{\circ}\right)$. 
values that corresponded to the $\mathrm{He}^{4}$ vapor pressures observed concurrently with the $\mathrm{He}^{3}$ vapor pressures.

The $1958 \mathrm{WAO}$ heat-of-vaporization data may be used to test the $1962 \mathrm{He}^{3}$ Scale in the manner explained by Durieux [15]. In terms of an apparent heat of vaporization, $L_{a}$ (defined as the heat necessary to evolve a mole of gas outside of a calorimeter), eq (6) becomes

$$
\begin{aligned}
L_{a} & =T V_{G}(d P / d T)_{\mathrm{sat}} \\
& =-R\left(1+B / V_{G}+C / V_{G}^{2}\right)[d \ln P / d(1 / T)]_{\mathrm{sat}} \\
& =R T^{2} Z(d \ln P / d T)_{\mathrm{sat}}
\end{aligned}
$$

where the compressibility coefficient, $Z \equiv\left(P V_{G} /\right.$ $R T)=\left(1+B / V_{G}+C / V_{G}^{2}\right)$ from the density virial form of the equation of state.

As shown in figure 4 , the observed values of $L_{a}$ average about 0.5 percent higher than the values calculated from the $1962 \mathrm{He}^{3}$ Scale using eq (8), a deviation considerably in excess of the estimated 0.1 percent accuracy [55] of the $L_{a}$ measurements. Durieux [15] calculates that the $L_{a}$ values of Berman and Mate [56] for $\mathrm{He}^{4}$ average 0.76 percent higher than the values calculated from the $1958 \mathrm{He}^{4}$ Scale between 2.2 and $3.0^{\circ} \mathrm{K}$. These differences may be due in part to a deviation of the $1962 \mathrm{He}^{3}$ and 1958 $\mathrm{He}^{4}$ Scales from the true thermodynamic temperature scale. An estimate of such a difference may be obtained by neglecting the variation of $(d \ln P / d T)_{\text {sat }}$ and $Z$ in eq (8). In this case $\delta T / T \approx(1 / 2)\left(\delta L_{a}\right) / L_{a}$. From the dashed curve drawn through the $\mathrm{He}^{3}$ data of figure 4 this estimate of $\delta T$ varies from $3 \mathrm{mdeg}$ at $1.2^{\circ} \mathrm{K}$ to $1 \mathrm{mdeg}$ at $2.0^{\circ} \mathrm{K}$, a not unreasonable range of deviations. For the $\mathrm{He}^{4}$ data, this approximation yields values from $8 \mathrm{mdeg}$ at $2.2^{\circ} \mathrm{K}$ up to 11 mdeg at $3.0^{\circ} \mathrm{K}$ which are much larger than appears reasonable for the departure of the $1958 \mathrm{He}^{4}$ Scale from the thermodynamic scale. An error in the temperature scale also would cause both $(d \ln P / d T)_{\text {sat }}$ and $Z$ to change.

\subsection{Fit of Gas Thermometer, Isotherm, and Acoustic Interferometer Measurements}

In principle, gas thermometer, isotherm and acoustic interferometer measurements of the absolute temperature associated with a $\mathrm{He}^{4}$ vapor pressure may be used to check the $1962 \mathrm{He}^{3}$ Scale by directly interpolating the $\mathrm{He}^{4}$ vapor pressure to an isothermal $\mathrm{He}^{3}$ vapor pressure. The direct interpolation equations and table described in Part I are usable for this interpolation of $\mathrm{He}^{4}$ vapor pressures. Since the $1962 \mathrm{He}^{3}$ Scale has been made to agree so closely with the $1958 \mathrm{He}^{4}$ Scale, at least in terms of the $\left(P_{3}, P_{4}\right)$ data of Part I, little really significant new information would be expected from this kind of comparison.

Van Dijk [57] has critically reanalyzed all published gas thermometer and isotherm measurements and compared them with the $1958 \mathrm{He}^{4}$ Scale. The majority of these measurements between 1.5 and $3.3^{\circ} \mathrm{K}$ seem to indicate that the thermodynamic

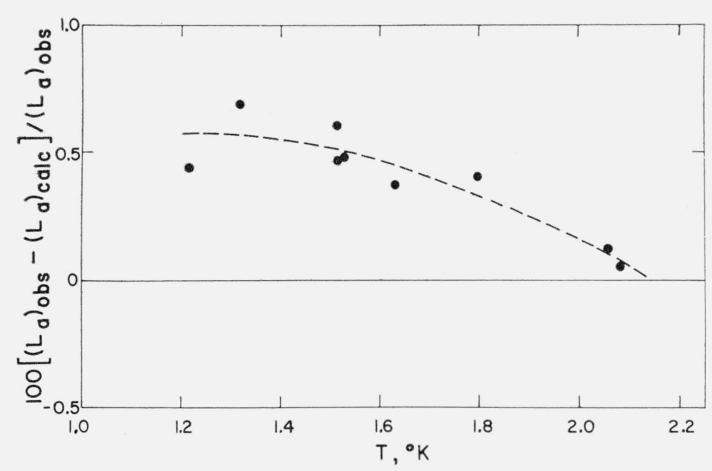

Figure 4.-Deviations of the values of $\mathrm{L}_{\mathrm{a}}$, the apparent latent heat of vaporization (see sec. 1.4), observed by Weinstock, Abraham, and Osborne $[4,55]$ from values of $\mathrm{L}_{\mathrm{a}}$ calculated for the $1962 \mathrm{He}^{3}$ Scale from eq (8) using eqs (10) and (11).

temperature may be several millidegrees higher than $T_{58}$, although the data scatter over a range of about \pm 10 mdeg from $T_{58}$.

Two preliminary acoustic interferometer results of Cataland and Plumb [58] indicate thermodynamic temperatures that are $3 \pm 2 \mathrm{mdeg}$ higher than $T_{58}$ at 2.0 and $2.2^{\circ} \mathrm{K}$.

The isotherm measurements of Keller [11, 12] are generally conceded to be the most accurate in the liquid helium temperature range, and are the only data for gaseous $\mathrm{He}^{3}$. During the derivation of the $1962 \mathrm{He}^{3}$ Scale, the isotherm data of Keller were reanalyzed [10, 48] by Deming's method [47] of least squares adjustment with errors in more than one measured variable (see appendix A). For the isotherm measurements the observed pressures for each data point were corrected or normalized to a calculated value which would have been observed if the cell volume were at the normalized temperature for the set of data points. This normalized temperature, $T_{N}, 58$, was taken as the temperature on the $1958 \mathrm{He}^{4}$ Scale corresponding to $\bar{P}_{4}$, the average $\mathrm{He}^{4}$ vapor pressure for the set of data. The values of $\bar{P}_{4}$ and $T_{N, 58}$ are listed in tables 2 and 3 . The method of normalization was essentially the same as that described in detail by Keller [11].

For the isotherm measurements the quantity minimized by the least squares adjustment was $\sum\left[W_{p}\left(P_{0}-P_{c}\right)^{2}+W_{n}\left(N_{0}-N_{c}\right)^{2}\right]$ where the independently observed variables are $P_{0}$, the normalized helium gas pressure, and $N_{0}$, the molar density. The fitted function was

$$
F\left(P_{c}, N_{c}\right)=P_{c}-N_{c} R T\left(1+B N_{c}+C N_{c}^{2}\right)=0
$$

where $B$ and $C$ are the second and third virial coefficients, $T$ is the isotherm temperature for a normalized set of data, and $P_{c}$ and $N_{c}$ are the calculated or adjusted values of $P$ and $N$. The individual weights, $W_{p}$ and $W_{n}$, were calculated from Keller's assignment of errors in the various observed quantities. 
TABLE 2. Summary of reanalysis of Keller's gaseous $\mathrm{He}^{3}$ isotherms [12]

The isotherm designations, the data points, and the method of normalization for each isotherm are the same as those used by Keller. $\bar{P}_{4}$ is the average He ${ }^{4}$ vapor pressure for each isotherm and $\bar{P}_{3}$ is the average $\mathrm{He}^{3}$ vapor pressure for the $\alpha$ isotherm. $T_{58}\left(\bar{P}_{4}\right)$ is the normalized temperature for each isotherm and is the $1958 \mathrm{He} \mathrm{P}^{4}$ Scale temperature corresponding to $\bar{P}_{4}, \quad P_{3}\left(\bar{P}_{4}\right)$ is the directly interpolated $\mathrm{He}^{3}$ vapor pressure corresponding to $\bar{P}_{4}$, using the direct interpolation equations described in Part I, and $T_{62}\left[P_{3}\left(\bar{P}_{4}\right)\right]$ is the $1962 \mathrm{He}^{3}$ Scale temperature corresponding to $P_{3}\left(\bar{P}_{4}\right)$. The values of $T_{\text {iso }}, B$, and $C$ listed under the heading “Three-constant fit" were obtained by solving eq (9) using Deming's method of least squares adjustment with errors in two measured variables (see appendix A). The standard errors and the weighted variance are calculated in accordance with the statistical formulas given by Deming [47]. The two constant fit values of $T$ iso and $B$ were obtained by solving eq (9) assuming $C=0$. For the For the $\gamma, \delta$, and $\epsilon$ isotherms the variance of the three-constant fit is lower and the values of $C$ are greater than the magnitude of their statistically assigned errors. Therefore the three constant fit solutions were used for fitting $\mathrm{He}^{3}$ virial coefficient equations, eqs (10) and (11), and for the temperature differences shown in figure 2 of Part II.

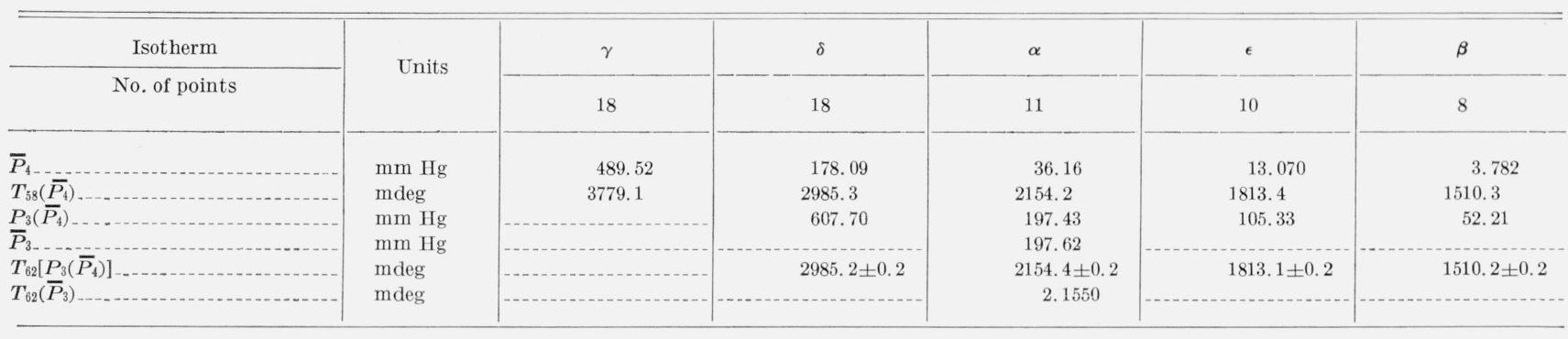

THREE-CONSTANT FIT

\begin{tabular}{|c|c|c|c|c|c|c|}
\hline 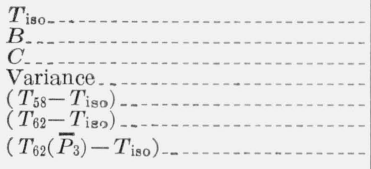 & $\begin{array}{l}\begin{array}{l}\text { mdeg } \\
\mathrm{cm}^{3} / \mathrm{mole} \\
\mathrm{cm}^{6} / \mathrm{mole}^{2}\end{array} \\
\text { mdeg } \\
\text { mdeg } \\
\text { mdeg }\end{array}$ & $\begin{array}{c}3782.3 \pm 2.2 \\
-65.50 \pm 0.86 \\
1192 \pm 306 \\
7.0 \\
-3.3 \pm 2.2\end{array}$ & $\begin{array}{l}2992.4 \pm 1.6 \\
-86.31 \pm 0.52 \\
1746 \pm 136 \\
13.8 \\
-7.1 \pm 1.6 \\
-7.2 \pm 1.8\end{array}$ & $\begin{array}{l}2153.7 \pm 1.0 \\
-118.81 \pm 1.35 \\
548 \pm 822 \\
6.1 \\
0.5 \pm 1.0 \\
0.7 \pm 1.2 \\
1.3 \pm 1.0\end{array}$ & $\begin{array}{c}1816.4 \pm 0.8 \\
-145.08 \pm 1.61 \\
2611 \pm 1289 \\
0.86 \\
-3.0 \pm 0.8 \\
-3.2 \pm 1.0\end{array}$ & $\begin{array}{c}1510.4 \pm 2.5 \\
-162.15 \pm 10.7 \\
-11,069 \pm 16,390 \\
4.8 \\
-0.1 \pm 2.5 \\
-0.2 \pm 2.7 \\
\end{array}$ \\
\hline \multicolumn{7}{|c|}{ TWO-CONSTANT FIT } \\
\hline $\begin{array}{l}T_{\text {iso }} \\
B \\
\text { Variance }\end{array}$ & $\begin{array}{l}\text { mdeg } \\
\mathrm{cm}^{3} / \text { mole }\end{array}$ & $\begin{array}{l}3774.4 \pm 1.3 \\
-62.18 \pm 0.19 \\
\quad 13.2\end{array}$ & $\begin{array}{l}2974.4 \pm 2.8 \\
-79.66 \pm 0.33 \\
156\end{array}$ & $\begin{array}{l}2153.2 \pm 0.6 \\
-117.92 \pm 0.26 \\
\quad 5.7\end{array}$ & $\begin{array}{l}1814.9 \pm 0.4 \\
-141.87 \pm 0.29 \\
\quad 1.20\end{array}$ & $\begin{array}{l}1512.0 \pm 0.7 \\
-169.30 \pm 1.15 \\
\quad 4.4\end{array}$ \\
\hline
\end{tabular}

TABLE 3. Summary of reanalysis of Keller's gaseous $\mathrm{He}^{4}$ isotherms [11]

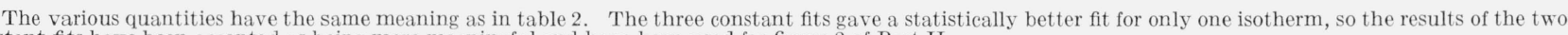
constant fits have been accepted as being more meaningful and have been used for figure 2 of Part II.

\begin{tabular}{|c|c|c|c|c|c|c|}
\hline Isotherm & Tnits & A & B & $\mathrm{C}$ & $\mathrm{D}$ & $\mathrm{E}$ \\
\hline No. of points & & 12 & 14 & 12 & 17 & 9 \\
\hline $\begin{array}{l}\overline{\mathrm{P}}_{4} \\
T_{58}\left(\overline{\mathrm{P}}_{4}\right) \\
P_{3}\left(\overline{\mathrm{P}}_{4}\right) \\
T_{62}\left[P_{3}\left(\overline{\mathrm{P}}_{4}\right)\right]\end{array}$ & $\begin{array}{l}\mathrm{mm} \mathrm{Hg} \\
\text { mdeg } \\
\mathrm{mm} \mathrm{Hg} \\
\text { mdeg }\end{array}$ & $\begin{array}{c}588.55 \\
3954.2\end{array}$ & $\begin{array}{c}291.31 \\
3339.2 \\
\end{array}$ & $\begin{array}{l}147.55 \\
2864.0 \\
528.42 \\
2864.0 \pm 0.2\end{array}$ & $\begin{array}{c}52.758 \\
2315.1 \\
254.50 \\
2315.0 \pm 0.2\end{array}$ & $\begin{array}{c}35.541 \\
2147.3 \\
195.21 \\
2147.6 \pm 0.2\end{array}$ \\
\hline
\end{tabular}

TWO-CONSTANT FIT

\begin{tabular}{|c|c|c|c|c|c|c|}
\hline $\begin{array}{l}T_{\text {iso }} \\
B \\
\text { Variance } \\
\left(T_{58}-T_{\text {iso }}\right) \\
\left(T_{62}-T_{i_{8}}\right)\end{array}$ & $\begin{array}{l}\begin{array}{l}\text { mdeg } \\
\mathrm{cm}^{3} / \mathrm{mole}\end{array} \\
\begin{array}{l}\mathrm{mdeg} \\
\mathrm{mdeg}\end{array}\end{array}$ & $\begin{array}{l}3953.7 \pm 2.1 \\
-83.97 \pm 0.66 \\
\quad 8.7 \\
-1.5 \pm 2.1 \\
\end{array}$ & $\begin{array}{c}3338.4 \pm 2.1 \\
-103.60 \pm 0.78 \\
17.8 \\
0.8 \pm 2.1\end{array}$ & $\begin{array}{l}2863.5 \pm 0.9 \\
-124.16 \pm 0.63 \\
\quad 3.6 \\
0.5 \pm 0.9 \\
0.5 \pm 1.1\end{array}$ & $\begin{array}{l}2316.7 \pm 2.3 \\
-153.38 \pm 4.21 \\
23.4 \\
-1.6 \pm 2.3 \\
-1.7 \pm 2.5\end{array}$ & $\begin{array}{l}2148.9 \pm 0.9 \\
-176.04 \pm 2.04 \\
\quad 1.69 \\
-1.6 \pm 0.9 \\
-1.3 \pm 1.1\end{array}$ \\
\hline
\end{tabular}

THREE-CONSTANT FIT

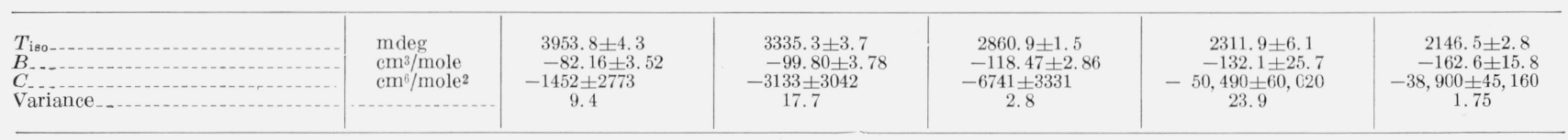


The results of the reanalysis of Keller's gaseous $\mathrm{He}^{3}$ data [12] were fitted to empirical equations for the $\mathrm{He}^{3}$ second and third virial coefficients. These equations are

and

$$
B=(4.942-270.976 / T) \mathrm{cm}^{3} / \mathrm{mole}
$$

$$
C=(2866 / \sqrt{T}) \mathrm{cm}^{6} / \text { mole }^{2} \text {. }
$$

The deviations of both $\mathrm{He}^{3}$ and $\mathrm{He}^{4}$ isotherm temperatures from the $1962 \mathrm{He}^{3}$ and $1958 \mathrm{He}^{4}$ Scales are shown in figure 2 of Part II. Keller used a $\mathrm{He}^{4}$ vapor-pressure thermometer for all but one of his isotherms, but his observed $P_{4}$ 's have been interpolated to $P_{3}$ 's by use of the direct interpolation equations of Part I. The weighted average of the isotherm temperatures is $1.50 \pm 1.0$ mdeg above the corresponding $T_{58}$ values and $1.52 \pm$ 1.2 mdeg above the $T_{62}$ values. For one isotherm $\mathrm{He}^{3}$ containing about 0.25 percent $\mathrm{He}^{4}$ was condensed in the vapor-pressure bulb. The corrected average pressure for pure $\mathrm{He}^{3}$ was $197.62 \pm 0.02 \mathrm{~mm}$ $\mathrm{Hg}\left(T_{62}=2.1550{ }^{\circ} \mathrm{K}\right)$ at an isotherm temperature of $2.1537 \pm 0.0010^{\circ} \mathrm{K}$. It was concluded that nothing would be gained by trying to base a $\mathrm{He}^{3}$ scale more directly on these isotherm temperatures since the $1958 \mathrm{He}^{4}$ Scale is based on these data. Moreover, the $1962 \mathrm{He}^{3}$ Scale, as it has been set up to agree with the $1958 \mathrm{He}^{4}$ Scale, adequately expresses the experimental $\mathrm{He}^{3}-\mathrm{He}^{4}$ vapor-pressure relation for most practical purposes.

\section{Thermodynamic Properties of $\mathrm{He}^{3}$ Con- sistent with the $1962 \mathrm{He}^{3}$ Scale}

Two temperatures which are frequently given in discussing helium vapor pressure scales are the boiling point and the critical point. The boiling point of $\mathrm{He}^{3}$ on the $1962 \mathrm{He}^{3}$ Scale, at a vapor pressure of $760 \mathrm{~mm} \mathrm{Hg}$ at $0{ }^{\circ} \mathrm{C}$ and standard gravity, is $3.1905{ }^{\circ} \mathrm{K}$. The temperature at the critic il point for $\mathrm{He}^{3}$ was measured by Sydoriak and Sherman [46] by observing the $\mathrm{He}^{4}$ vapor pressure.
This measured critical temperature on the 1958 $\mathrm{He}^{4}$ Scale was $3.3240 \pm 0.0018^{\circ} \mathrm{K}$ at a $\mathrm{He}^{3}$ critical pressure, $P_{c}$, of $873.0 \pm 1.5 \mathrm{~mm} \mathrm{Hg}$. The calculated critical temperature on the $1962 \mathrm{He}^{3}$ Scale is the temperature given by eq (9b) of Part II [6] corresponding to $P_{c}$ and is $3.3246 \pm 0.0017{ }^{\circ} \mathrm{K}$. This close agreement with the directly measured temperature is quite gratifying and somewhat unexpected since the scale-defining equation was fitted over the full range of the vapor-pressure intercomparisons.

Table 4 gives a number of quantities which are consistent with the $1962 \mathrm{He}^{3}$ Scale, including, for comparison, values of $\mathrm{He}^{4}$ vapor pressures from the $1958 \mathrm{He}^{4}$ Scale. The concentration derivative of ln $P_{X},\left(d \ln P_{X} / d X\right)_{T, X=1}$, where $X$ is the mole fraction of $\mathrm{He}^{3}$ and $P_{X}$ is the corresponding mixture vapor pressure, is useful for correcting for the $\mathrm{He}^{4}$ impurity in a $\mathrm{He}^{3}$ vapor-pressure thermometer. This correction is discussed in section 3 .

The table values for $C_{\mathrm{sat}}$, the specific heat of the saturated liquid, were calculated from the empirical equation, eq (3b) of Part II, fitted to specific-heat data for the derivation of the $1962 \mathrm{He}^{3}$ Scale. The calculated values agree with the experimental data to \pm 1 percent; the deviations are given in table 2 of Part II. Values for $S_{L}$, the entropy of the saturated liquid, were calculated from the relation

$$
S_{L}(T)=S_{L}\left(1.0^{\circ}\right)+\int_{1.0}^{T}\left(C_{\text {sat }} / T^{\prime}\right) d T^{\prime}
$$

using the above-mentioned $C_{\text {sat }}$ equation and the $1962 \mathrm{He}^{3}$ Scale value of $S_{L}\left(1.0^{\circ}\right)$, given in eq (4).

Values for the second and third virial coefficient were calculated from eqs (10) and (11) while $V_{G}$, the molar volume of the saturated vapor, was calculated from the equation given for $Z$ in eq (8). These calculated values of $V_{G}$ agree to within 1 percent with the smoothed fit to the experimental data of Kerr [59] up to $2.8{ }^{\circ} \mathrm{K}$. The values of $V_{L}$, the molar volume of the saturated liquid, are taken from the table of Kerr and Taylor [60]. The values of $L$, the heat of vaporization, are calcu-

\begin{tabular}{|c|c|c|c|c|c|c|c|c|c|c|c|}
\hline \multirow{2}{*}{$T$} & \multirow{2}{*}{$P_{3}$} & \multirow{2}{*}{$P_{4}\left(T_{58}\right)$} & \multirow{2}{*}{$\left(\frac{d \ln P 3}{d T}\right)$} & \multirow{2}{*}{$\begin{array}{c}\left(\frac{d \ln P_{X}}{d X}\right)_{T} \\
\text { at } \\
X=1 \\
\text { (see note } \dagger \text { ) }\end{array}$} & \multirow{2}{*}{$C_{\text {sat }}$} & \multirow{2}{*}{$S_{L}$} & \multicolumn{2}{|c|}{ Virial coeff. } & \multirow{2}{*}{$V_{G}$} & \multirow{2}{*}{$V_{L}$} & \multirow{2}{*}{$L$} \\
\hline & & & & & & & B & $\mathrm{C}$ & & & \\
\hline${ }^{\circ} K$ & \multicolumn{2}{|c|}{ microns $\mathrm{Hg}$ at $0^{\circ} \mathrm{C}$ and std. $\mathrm{g}$} & $\operatorname{deg}^{-1}$ & & J/deg mole & J/deg mole & $\mathrm{cm}^{3} /$ mole & $\mathrm{cm}^{6} / \mathrm{mole}^{2}$ & $\mathrm{~cm}^{3} /$ mole & $\mathrm{cm}^{3} /$ mole & J/mole \\
\hline 0.2 & 0.0121 & & 73.32 & 0.23 & 2.728 & 3. 703 & -1350 & 6409 & $103 \times 10^{7}$ & $\begin{array}{l}36.7809 \\
36\end{array}$ & 24.39 \\
\hline $\begin{array}{l}0.4 \\
0.6\end{array}$ & $\begin{array}{l}28.115 \\
544.49\end{array}$ & C. 2812 & $\begin{array}{l}21.04 \\
10.57\end{array}$ & $\begin{array}{l}0.47 \\
0.70\end{array}$ & $\begin{array}{l}\text { 3. } 146 \\
3.477\end{array}$ & $\begin{array}{l}5.731 \\
7.071\end{array}$ & $\begin{array}{l}-672.5 \\
-446.7\end{array}$ & $\begin{array}{l}4532 \\
3700\end{array}$ & $887 \times 10^{3}$ & $\begin{array}{l}36.7203 \\
36\end{array}$ & 27.97 \\
\hline 0.8 & 2892.5 & 11.445 & 6.650 & 0.88 & $\begin{array}{l}3.411 \\
3.812\end{array}$ & 8.117 & $\begin{array}{l}-440.1 \\
-233.8\end{array}$ & 3204 & $\begin{array}{l}16909 \\
1699\end{array}$ & $\begin{array}{l}\text { 50. } 1979 \\
36.7849\end{array}$ & $\begin{array}{l}31.42 \\
34.61\end{array}$ \\
\hline 1.0 & 8842.4 & 120.00 & 4.721 & 0.92 & 4.222 & 9.010 & -266.0 & 2866 & 6776.6 & 36.9673 & 37.51 \\
\hline 1.2 & 20163 & 625. 02 & 3.613 & 0.92 & 4.753 & 9.824 & -220.9 & 2616 & 3476.7 & 37. 0897 & 40.08 \\
\hline 1.4 & 38516 & 2155.4 & 2. 908 & 0.91 & 5.414 & 10.605 & -188.6 & 2422 & 2060.7 & 37.3517 & 42.29 \\
\hline 1.6 & 65467 & 5689.9 & 2.425 & 0.89 & 6.201 & 11.378 & -164.4 & 2266 & 1338.9 & 37.7151 & 44.07 \\
\hline 1.8 & 102516 & 12466 & 2.077 & 0.88 & 7. 079 & $\begin{array}{l}12.159 \\
\end{array}$ & -145.6 & 2136 & $\begin{array}{r}925.5 \\
\end{array}$ & $\begin{array}{l}38.201 \\
\text { (1) }\end{array}$ & 45.34 \\
\hline $\begin{array}{l}2.0 \\
2.0\end{array}$ & 151112 & 23767 & 1.815 & $\begin{array}{l}0.86 \\
0.86\end{array}$ & 7.983 & 12.951 & $\begin{array}{l}-130.0 \\
-130.6\end{array}$ & 2027 & 667.8 & $\begin{array}{l}28.854 \\
28.854\end{array}$ & $\begin{array}{l}45.99 \\
45.99\end{array}$ \\
\hline 2.2 & 212673 & 40466 & 1.611 & 0.810 & & 12.901 & $\begin{array}{l}118.0 \\
-118.2\end{array}$ & 1932 & 496.6 & 39.680 & 45.91 \\
\hline 2.4 & 288613 & 63304 & 1.448 & 0.781 & & ....... & -108.0 & 1850 & 376.7 & 40.734 & 44. 94 \\
\hline 2.6 & 380383 & 93733 & 1.317 & 0.754 & & & -99.3 & 1777 & 288.8 & 42.124 & 42.84 \\
\hline 2.8 & 489549 & 132952 & 1. 210 & 0.728 & & & -91.8 & 1713 & 221.0 & 44. 049 & 39.11 \\
\hline 3. 0 & 617907 & 182073 & 1.122 & 0.705 & & & -85.4 & 1655 & 163.1 & 46.818 & 32.25 \\
\hline
\end{tabular}
lated from eq (6).

TABLE 4. Thermodynamic properties of $\mathrm{He}^{3}$ and vapor pressures of $\mathrm{He}^{4}$ consistent with the 1962 $\mathrm{He}^{3}$ Scale

$\nmid$ Here $\mathrm{X}$ is the $\mathrm{He}^{3}$ mole fraction. The $\mathrm{He}^{t}$ mole fraction, $(1-\mathrm{X})$, is used to make the impurity correction. 
The heat of vaporization at absolute zero, $L_{0}$, can be obtained from the fitted constant, $a$, of eq (3) if the specific heat integral is evaluated. The specific heat of liquid $\mathrm{He}^{3}$ under a pressure of a few centimeters of mercury has been measured by Anderson, Wheatley, and coworkers [61] down to a temperature of $0.015^{\circ} \mathrm{K}$. Their empirical equation for $C_{p}$, the specific heat at a constant pressure of 0.12 atm, is $\left(C_{p} / R\right)=2.89 T-7.80 T^{2}+7.09 T^{3}$ for $0<T<0.3^{\circ}$. Integration of this equation yields $\int_{0}^{0.2} C_{\mathrm{sat}} d T \approx \int_{0}^{0.2} C_{p} d T=0.331 \pm 0.013 \mathrm{~J} / \mathrm{mole}$. This value is in excellent agreement with the value $0.333 \pm 0.010 \mathrm{~J} / \mathrm{mole}$ obtained by graphical integration of the smooth curve through recent specific heat data given by Strongin, Zimmerman, and Fairbank [62]. From the empirical equation for $C_{\text {sat }}$ used for the $T_{62}$ scale, $\int_{0.2}^{1.0} C_{\text {sat }} d T=2.784 \pm 0.056$ $\mathrm{J} / \mathrm{mole}$. Our corresponding value of $L_{0}$ is 20.56 $\pm 0.07 \mathrm{~J} / \mathrm{mole}$.

The entropy of the saturated liquid can be assumed to be approximately equal to $\int_{0}^{T}\left(C_{p} / T^{\prime}\right) d T^{\prime}$ from the $0.12 \mathrm{~atm} C_{p}$ equation of Anderson et al. [61] given above. From this approximation $S_{L}\left(0.23^{\circ} \mathrm{K}\right)$ is $4.05 \pm 0.17 \mathrm{~J} /$ mole deg. Strongin et al. [62] also have computed the entropy from their extrapolation of specific heat data to $0{ }^{\circ} \mathrm{K}$. Their value for the entropy at $0.23{ }^{\circ} \mathrm{K}$ is $3.97 \pm 0.17 \mathrm{~J} / \mathrm{mole} \mathrm{deg}$. These values are in good agreement with the value $4.02 \pm 0.25 \mathrm{~J} / \mathrm{mole}$ deg obtained by Weinstock, Abraham and Osborne [4], who used eq (5) to calculate $S_{L}\left(1.5^{\circ}\right)$ from their three separate latent heat measurements at that temperature. The equivalent of eq (12) was used by WAO to compute other entropies in the range of the then available specific heat data. The value of $S_{L}\left(0.23^{\circ}\right)$ consistent with the $1962 \mathrm{He}^{3}$ Scale, calculated from eq (12), is $S_{L}\left(0.23^{\circ}\right)=4.09 \pm 0.10 \mathrm{~J} / \mathrm{mole} \mathrm{deg}$, estimating $\mathrm{a} \pm 2$ percent limit of error for the specific heat integral term. The good agreement among these values is gratifying but it may be fortuitous. For example, the $\mathrm{He}^{3}$ temperature scale used by Weinstock et al. [4] to assign temperatures to observed $\mathrm{He}^{3}$ vapor pressures was the $T_{L}$ Scale, eq (9) of ref. [9]. The deviations of the $T_{L}$ Scale from the $1962 \mathrm{He}^{3}$ Scale are shown in figure 5 and range from +6 to -3 mdeg. At $1.5^{\circ} \mathrm{K}$, however, the two scales are in good agreement as to the temperature. Thus the value of $T$ used in computing both $S_{G}$ and $L / T$ in eq (7) would give essentially the same value for liquid entropy at $T \approx 1.5^{\circ} \mathrm{K}$ on the $T_{L}$ and $1962 \mathrm{He}^{3}$ Scales. If, however, a value of $L$ calculated from eq (6) is used in eq (7) instead of a WAO experimental value of $L$, significantly different values are obtained for $S_{L}$ depending upon which of the two scales, $T_{L}$ or $1962 \mathrm{He}^{3}$, is used for the calculation of $\left(d P_{3} / d T\right)_{\text {sat }}$ since there is a difference of about 0.4 percent in these derivatives on the two scales as inferred from the slope of the $\Delta T$ curve in figure 5 (see, for example, ref. [63]).

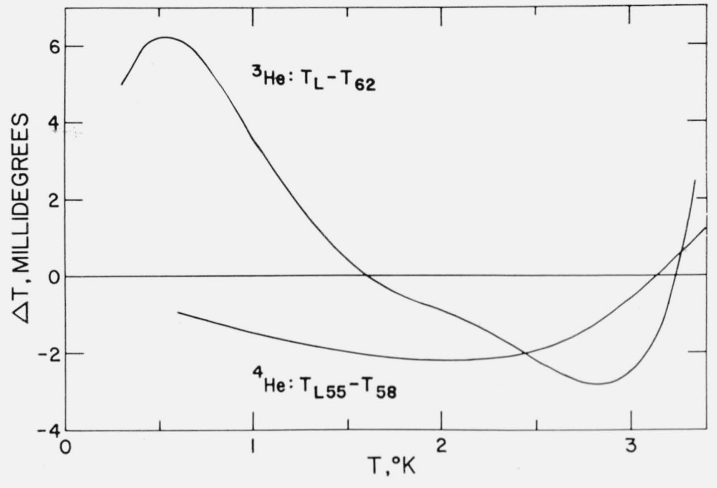

Figure 5.- Graphs of differences between old and new $\mathrm{He}^{3}$ and $\mathrm{H}^{4}$ temperature scales.

The He $\mathrm{H}^{3}$ curve, $T_{L}\left(P_{3}\right)-T_{62}\left(P_{3}\right)$, is a graph of the difference between the $T_{L}$ Scale [9] and the $1962 \mathrm{He}^{3}$ Scale. The He curve is the difference between the $T_{L 55}$ Scale [25] and the $1958 \mathrm{He}^{4}$ Scale given in table 6 of ref [2]. It was intended in their derivations that the $T_{L}$ Scale would reproduce the $T_{L 55}$ Scale, and that the $1962 \mathrm{He}^{3}$ Scale would reproduce the $1958 \mathrm{He}^{4}$ Scale. The difference between the two curves is explained principally by the new $\left(P_{3}, P_{4}\right)$. intercomparison data of Sydoriak and Sherman [46] used in deriving the $1962 \mathrm{He}^{3}$ Scale.

\section{Corrections to the Measured Pressure of a $\mathrm{He}^{3}$ Vapor-Pressure Thermometer for the $\mathrm{He}^{4}$ Impurity}

Sydoriak and Sherman have discussed in Part I corrections to be applied to an observed pressure as measured in the laboratory in order to obtain the vapor pressure at the surface of liquid $\mathrm{He}^{3}$. The correction for a small $\mathrm{He}^{4}$ impurity will be discussed in more detail here.

The presence of $\mathrm{He}^{4}$ in liquid $\mathrm{He}^{3}$ thermometers lowers the vapor pressure below that of pure $\mathrm{He}^{3}$. Much of the $\mathrm{He}^{3}$ available for purchase up to the present has contained significant quantities of $\mathrm{He}^{4}$; even the $\mathrm{He}^{3}$ used for the $1962 \mathrm{He}^{3}$ Scale input data measurements [46] contained about 0.04 percent $\mathrm{He}^{4}$. Specially purified $\mathrm{He}^{3}$ containing less than 0.01 percent is being made available for purchase through the Division of Research of the United States Atomic Energy Commission [64].

The correction for small amounts of $\mathrm{He}^{4}$ may be calculated from the approximate relation

$$
P_{3}-P_{x} \approx(1-X)\left(d P_{x} / d X\right)_{T, X=1}
$$

where $P_{x}$ is the observed vapor pressure for mole fraction, $X$, of $\mathrm{He}^{3}$. Although very little data has been published for the vapor pressures of dilute solutions of $\mathrm{He}^{4}$ in $\mathrm{He}^{3}$, the liquid phase diagrams of Sydoriak and Roberts [32] and Esel'son and Berezniak [38] indicate that $\left(d P_{x} / d X\right)_{T}$ is probably a constant for $X \geq 0.9$ and hence eq (13) may be valid for concentrations of up to 10 percent $\mathrm{He}^{4}$. Smooth values of this derivative in reduced form,

$\left(d \ln P_{x} / d X\right)_{T, X=1}=\left(1 / P_{3}\right)\left(d P_{x} / d X\right)_{T, X=1}$

$$
\approx\left[1-\left(\frac{P_{x}}{P_{3}}\right)\right] /(1-X)
$$


are listed in table 4 and are compared with the raw data of Sydoriak and Roberts [32] in figure 6 . Between 0.6 and $2.0^{\circ} \mathrm{K}$ the table 4 entries and the solid curve in figure 6 were calculated from eq (14) using the $X=0.9$ values from the smoothed table of ref. [32]. Below $0.6{ }^{\circ} \mathrm{K}$ the derivative has been assumed to go linearly to zero at $0{ }^{\circ} \mathrm{K}$ mainly because such an extrapolation is consistent with the data below $1{ }^{\circ} \mathrm{K}$, as shown in figure 6 . Actually for all practical purposes this derivative may be zero below about $0.2{ }^{\circ} \mathrm{K}$ since at these temperatures liquid $\mathrm{He}^{3}-\mathrm{He}^{4}$ mixtures with very small amounts of $\mathrm{He}^{4}$ undergo phase separation [65] and, when this happens, the vapor pressure becomes independent of further decreases in $X$. Above $2.0^{\circ} \mathrm{K}$, the table 4 values were calculated from Raoult's law,

$$
\left(d \ln P_{x} / d X\right)_{T, X=1}=1-\left(P_{4} / P_{3}\right),
$$

shown as the dashed curve in figure 6 . That law is in fairly good agreement with all existing vaporpressure data for $X \geq 0.89$ and $T \geq 1.7^{\circ} \mathrm{K}$.

The concentration of $\mathrm{He}^{4}$ in the saturated vapor will be much less than that of the liquid. This fact can cause fractionation and may require further correction in precise thermometry if much of the $\mathrm{He}^{3}$ in the thermometer system is not condensed.

The correction to a temperature measurement made with a $\mathrm{He}^{3}$ sample containing 0.1 percent $\mathrm{He}^{4}$ in the liquid phase ranges from $0.02 \mathrm{mdeg}$ at $0.4^{\circ} \mathrm{K}$ to $0.71 \mathrm{mdeg}$ at $3.2^{\circ} \mathrm{K}$. For most purposes the correction may be calculated from the approximate relation

$$
P_{3}-P_{x} \approx(1-X) P_{x}\left(d \ln P_{x} / d X\right)_{T, X=1} .
$$

The derivative below $2{ }^{\circ} \mathrm{K}$ may be interpolated from a curve through the values listed in table 4 or from figure 6 . Above $2{ }^{\circ} \mathrm{K}$ the derivative can be easily calculated from eq (15). A careful experimental determination of the correction above $2{ }^{\circ} \mathrm{K}$ would improve the accuracy of this correction.

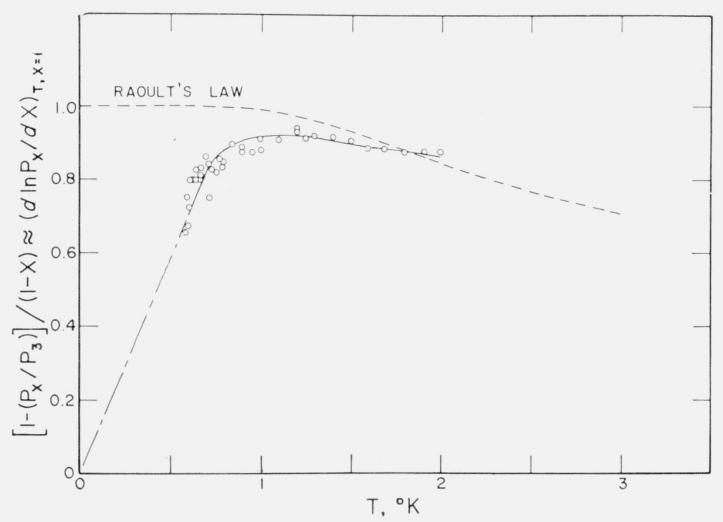

Figure 6. - The correction factor for $\mathrm{He}^{4}$ impurity.

The circles are the data points of Sydoriak and Roberts [32] for $\mathrm{He}^{3}$ mole fraction, $X$, of 0.897 . The solid curve from 0.6 to $2.0^{\circ} \mathrm{K}$ is drawn through the smoothed table values of ref. [32] for $X=0.9$. The long and short dashed curve is an arbitrary extrapolation to $0^{\circ} \mathrm{K}$. The dashed curve is Raoult's Law, eq (15).

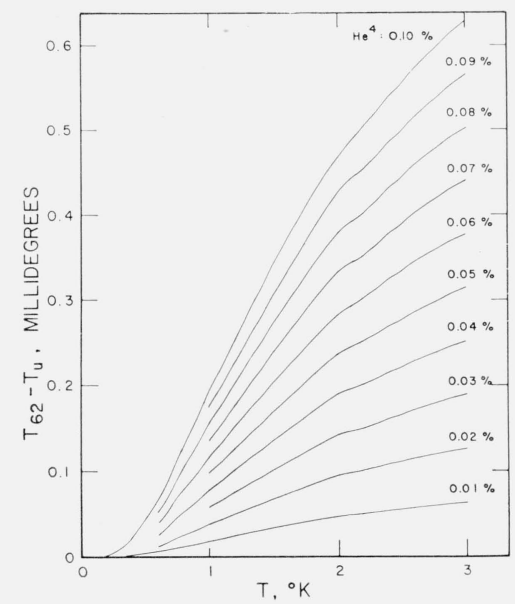

Figure 7.-Correction for $\mathrm{He}^{4}$ impurity, $\left(\mathrm{T}_{62}-\mathrm{T}_{\mathrm{u}}\right)$, to be added to the uncorrected temperatures, $\mathrm{T}_{\mathrm{u}}$, calculated from the observed vapor pressure and the 1962 $\mathrm{He}^{3}$ Scale.

The correction is calculated as $T_{62}-T_{u}=(1-X)\left(d \ln P_{x} / d X\right)_{T}, X=1 /\left(d \ln P_{3} / d T\right)$ based on eqs (13) and (14) and using the derivative values listed in table 4 . The curves can be used for ten times the indicated percent of $\mathrm{He}^{4}$ in the liquid if the ordinate is multiplied by ten.

Figure 7 may be used to read the temperature correction directly for known $\mathrm{He}^{4}$ concentrations in the liquid.

\section{Status of the $1962 \mathrm{He}^{3}$ Scale of Tem- peratures}

The $1962 \mathrm{He}^{3}$ Scale was presented [66] at the Eighth International Conference on Low Temperature Physics in London, September 17-21, 1962. During the next week the new scale was discussed in detail by the Advisory Committee on Thermometry of the International Committee on Weights and Measures. A scale proposal along with ref. [54] has been published along with the minutes of the meeting of the Advisory Committee in Sèvres, France, September 26 and 27, 1962. Quoting from the draft of those minutes [67]:

"Il a estimé que l'Échelle ${ }^{3} \mathrm{He} 1962$ doit également être recommandée pour l'usage général, avec la désignation $T_{62}$.

"Les deux échelles $T_{58}$ (l'Échelle ${ }^{4} H e$ 1958) et $T_{62}$ peuvent être utilisées concurremment dans le domaine où elles sont valables. Cependant, quand il s'agit de l'adoption de cette nouvelle échelle ${ }^{3} \mathrm{He}$ comme partie de l'E.I.P.T., on doit prendre soin d'éviter toute ambiguité dans le domaine de recouvrement avec l'échelle ${ }^{4} \mathrm{He} . "{ }^{3}$

The recommendation by the Advisory Committee of the $1962 \mathrm{He}^{3}$ Scale was approved in October 1962, by the International Committee on Weights and

3 "It (the Advisory Committee) has deemed that the $1962 \mathrm{He}^{3}$ Scale ought equally to be recommended for general usage with designation $T_{62}$.

"The two scales $T_{58}$ and $T_{62}$ can be used concurrently in the range where they are valid. However, when it is a question of adopting this new $\mathrm{He}^{3}$ scale as a part of the I.P.T.S. (International Practical Temperature Scale), care should be taken to avoid any ambiguity in the region of overlap with the He $\mathrm{H}^{4}$ scale. 
Measures meeting in Sèvres. The International Committee requested the United States and Russian Governments to take steps to make high-purity $\mathrm{He}^{3}$ a vailable internationally for vapor-pressure thermometry, and to prepare and distribute known mixtures of $\mathrm{He}^{3}$ and $\mathrm{He}^{4}$ for the calibration of or the checking of the calibration of apparatus for measuring the isotopic purity of $\mathrm{He}^{3}$.

The status of the $1962 \mathrm{He}^{3}$ Scale and proposed changes in the International Practical Temperature Scale have been discussed by Stimson [68] and Brickwedde [69].

\section{Practical Lower Limits for $\mathrm{He}^{3}$ and $\mathrm{He}^{4}$ Vapor-Pressure Thermometry}

Practical lower limits for helium vapor-pressure thermometry are determined by the desired precision of temperature determination, the accuracy with which the vapor pressure can be measured, and by how small or how well known the temperature difference is between the thermometric fluid and the object of the measurement.

Below about $2.2^{\circ} \mathrm{K}, \mathrm{He}^{3}$ can much more easily be made isothermal with an object the temperature of which is being measured than can $\mathrm{He}^{4}$, for the reasons discussed in Part I. A major factor in fixing a practical lower limit for $\mathrm{He}^{3}$ thermometry is the time necessary to achieve an equilibrium thermomolecular ratio, $P_{c} / P_{w}$, of cold pressure, $P_{c}$, to warm pressure, $P_{w}$, and more importantly, of sufficient data to permit accurate calculation of that ratio.

To measure temperatures from 0.3 to $0.25^{\circ} \mathrm{K}$ to a millidegree precision using $\mathrm{He}^{3}$, vapor pressures from 1.9 to $0.24 \mu$ would have to be measured to 4 or 5 percent accuracy. This accuracy in the pressure system is relatively easy to achieve. However, the error in $P_{c} / P_{w}$ may amount to several percent because of marked quantum effects in the gas viscosity and because no $\mathrm{He}^{3}$ measurements have been made of the empirical thermal transpiration coefficients postulated by Weber [70]. The $\mathrm{He}^{3}$ thermomolecular pressure measurements made by Roberts and Sydoriak [37] showed that for a cold temperature of $2{ }^{\circ} \mathrm{K}$ observed $\mathrm{He}^{3} P_{c} / P_{w}$ ratios from 1.0 to 0.5 agreed within 1 percent with ratios calculated for $\mathrm{He}^{4}$ using the Weber-Schmidt equation [71].

Roberts and Sydoriak also discuss the possible effect of the low-temperature viscosity on pressure ratios in the tubing at liquid helium temperatures. For warm and cold temperatures, $T_{w}$ and $T_{c}$, below $5{ }^{\circ} \mathrm{K}$ and pressure ratios close to 1 , eq (5) of ref. [37] is $\left(p_{c} / p_{w}\right)^{2}=1-0.005642\left(T_{w}{ }^{2}-T_{c}{ }^{2}\right) /\left(R p_{w}\right)^{2}$ where $R$ is the tubing radius in centimeters and $p_{w}$ is in microns of mercury. In order to be reasonably sure that the calculated thermomolecular ratio is within 4 or 5 percent of the true ratio for $\mathrm{He}^{3}$ it is suggested that the calculated $\left(p_{c} / p_{w}\right)$ be kept greater than 0.5 in the rest of the pressure sensing tube. For the stepped pressure sensing tube used by Sydoriak and Sherman with dimensions shown in figure 4 of Part I [46], this suggests a practical lower limit of $R p_{c}=$ $0.155 \mathrm{~cm}$ microns or a vapor pressure of $1.16 \mu$ $\left(T_{62}=0.287^{\circ}\right)$.
The practical lower limit for $\mathrm{He}^{4}$ vapor-pressure thermometry is strongly dependent on numerous details of the particular technique and apparatus used. In many cases experimental temperatures are determined from the vapor pressure of the bath in which the experimental apparatus is immersed. For bath temperatures and with proper corrections for pressure drops associated with film reflux and/or motion of effluent vapor from the bath, temperatures may be determined down to about $1{ }^{\circ} \mathrm{K}$. Figure 1 of Part I shows errors due to film reflux pressure drops for typical sizes of pressure sensing tubing. However, for temperatures determined by thermal contact with a closed-bulb $\mathrm{He}^{4}$ vapor-pressure thermometer the practical lower limit is raised to just below the $\lambda$ point, because of the large and variable temperature discontinuity at the bulb wall associated with recondensation of the refluxing film. Figure 1 of Part I also shows this "correction" for a variety of conditions.

If the bulb wall is a poor thermal conductor, a still higher limit is imposed due to the effects of the density maximum at about $2.18{ }^{\circ} \mathrm{K}$, discussed by Chase, Maxwell, and coworkers [72].

In the case of precision measurements using $\mathrm{He}^{3}$ thermometry, the publication of only a few pertinent details, such as the diameters and temperatures of any stepped junctions in the pressure sensing tube, will enable future correction of data as improved thermal transpiration corrections become possible.

\section{Conclusion and Considerations for the Future}

These papers on the development of the $1962 \mathrm{He}^{3}$ Temperature Scale have emphasized marked differences between liquid $\mathrm{He}^{3}$ and $\mathrm{He}^{4}$. One is in the low-temperature variation of the liquid entropy. The quantum mechanical exchange forces in liquid $\mathrm{He}^{3}$ lead to appreciable correlation of the nuclear spins in the liquid at temperatures as high as $1^{\circ} \mathrm{K}$. The difficulty in fitting the entropy curve with a simple analytical expression has led to difficulty in attaching theoretical significance to certain terms in empirical vapor-pressure equations at temperatures below the temperature of fitted data.

The superfluid transition of liquid $\mathrm{He}^{4}$ makes accurate isothermal intercomparisons of $\mathrm{He}^{3}$ and $\mathrm{He}^{4}$ vapor pressures difficult below the $\mathrm{He}^{4} \lambda$-point. The 1961 intercomparison data of Sydoriak and Sherman [46], however, are considered to be valid to a few tenths of a millidegree. The $1962 \mathrm{He}^{3}$ Scale, which is based on these intercomparisons, is believed to be in agreement with the $1958 \mathrm{He}^{4}$ Scale to within two or three tenths of a millidegree over the full range of the intercomparison data, from $0.9^{\circ} \mathrm{K}$ to the critical point, $3.324{ }^{\circ} \mathrm{K}$. A lower limit for practical $\mathrm{He}^{3}$ vapor-pressure thermometry is $0.25^{\circ} \mathrm{K}$ corresponding to a $\mathrm{He}^{3}$ vapor pressure of $0.24 \mu \mathrm{Hg}$.

A number of independent measurements, including measurements of the latent heats of vaporization of $\mathrm{He}^{3}$ and $\mathrm{He}^{4}$, precise isotherm measurements, and preliminary acoustical interferometer measurements, 
indicate that both the $1962 \mathrm{He}^{3}$ Scale and the 1958 $\mathrm{He}^{4}$ Scale may be 2 or 3 mdeg lower than true thermodynamic temperatures between 1 and $3.3^{\circ} \mathrm{K}$. When more accurate data on the thermodynamic properties of $\mathrm{He}^{3}$ and $\mathrm{He}^{4}$ are available, together with better determinations of absolute thermodynamic temperatures, the precise intercomparison data will allow both the $\mathrm{He}^{3}$ and the $\mathrm{He}^{4}$ scales to be adjusted consistently and simultaneously. $\mathrm{He}^{3}$ and $\mathrm{He}^{4}$ scales, thermodynamically consistent between 1 and $3^{\circ} \mathrm{K}$, may be extended by precision paramagnetic salt thermometry above $3^{\circ} \mathrm{K}$ using $\mathrm{He}^{4}$ and below $1^{\circ} \mathrm{K}$ using $\mathrm{He}^{3}$. Also, the scales may be extended downward by thermodynamic calculations, using coefficients evaluated between 1 and $3{ }^{\circ} \mathrm{K}$ as in the development of the $1962 \mathrm{He}^{3}$ Scale and the $T_{L \overline{5} 5} \mathrm{He}^{4}$ Scale [25]. Further measurements on $\mathrm{He}^{3}$ that would be helpful in improving the Scale are measurements of the vapor pressure and thermomolecular pressure ratio down to temperatures of $0.25^{\circ} \mathrm{K}$, more accurate specific heat measurements on the liquid below $2{ }^{\circ} \mathrm{K}$, and specific heat, latent heat, and high-precision vapor-density measurements above $2{ }^{\circ} \mathrm{K}$.

\section{Appendix A. Method of Multiple Vari- able Least Squares Analysis}

In the usual least squares adjustment of experimental data the implicit assumption is made that only one measured quantity, often called the dependent variable, is in error. This dependent variable is measured as a function of one or more independent variables. The usual procedures for the adjusting of sets of observations to an empirical or theoretical equation assume no error in the independent variables. Frequently, however, the "independent variable" is also determined by a physical measurement and is just as subject to error as the dependent variable.

Deming [47] has discussed a method of adjustment of sets of observations of two or more variables when all variables are subject to error. His method is essentially equivalent to statistical weighting of the data. The method has been coded by $\mathrm{P}$. McWilliams of the Los Alamos laboratory for use with the Gaussian method of iterative least squares analysis adapted by Moore and Zeigler [73] for highspeed computers. We will give a simple example of the method of analysis with exaggerated scatter and uncertainty.

\subsection{Simple Example}

As a simple illustration consider fitting the best straight line to the following three points:

$$
\begin{array}{cc}
X & Y \\
1 \pm 1 & 1 \pm 1 \\
4 \pm 1 & 5 \pm 1 \\
5 \pm 1 & 4 \pm 1
\end{array}
$$

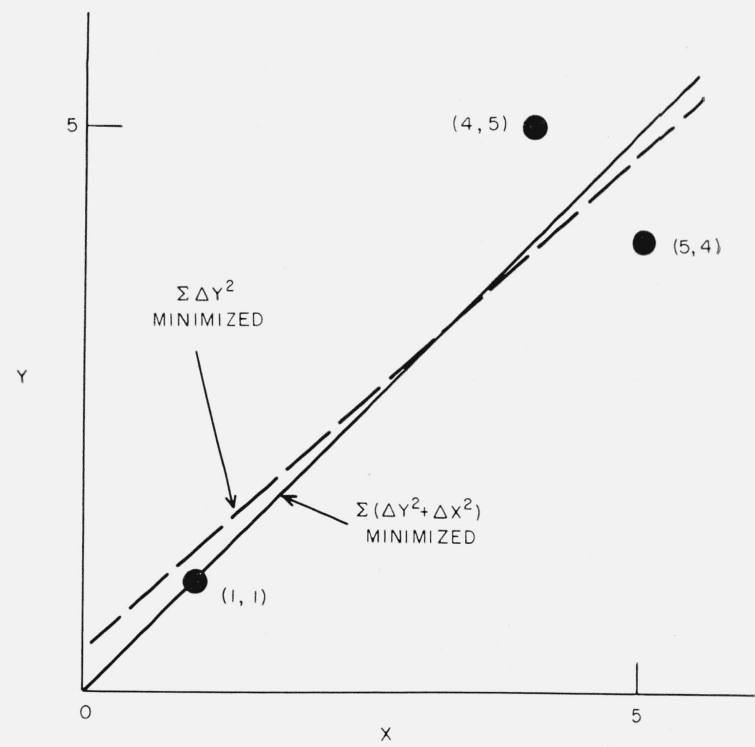

FiguRE 8.- Simple example of the least squares fit of a straight line to the three observed points shown as dots.

The dashed line is the usual least squares solution of $Y=a+b X$ which minimizes $\Sigma\left(Y_{o}-Y_{c}\right)^{2}$. The solid line is the solution assuming both $X$ and $Y$ are subject to equal absolute errors.

The dashed line in figure 8 shows the fit of the usual least squares solution of $Y=a+b X$ assuming that only $Y$ is in error and equally weighting the points. The solid line, $Y=X$, is the solution assuming that the $X$ and $Y$ values are all equally subject to equal absolute errors. The general case of fitting to a straight line is discussed in detail by Deming. For our special case of equal weighting, the two solutions go through the centroid but have different slopes.

Actually the quantity which is minimized by the least squares solution is

$$
S=\sum_{i=1}^{M}\left[w_{y, i}\left(Y_{o, i}-Y_{c, i}\right)^{2}+w_{x, i}\left(X_{o, i}-X_{c, i}\right)^{2}\right]
$$

where the subscript $o$ indicates the observed value; subscript $c$ indicates the calculated or adjusted value; and $w_{y, i}$ and $w_{x, i}$ are the weights of the $i$ th of $M$ sets of observations. Thus in figure 8 the solid line is identified as minimizing

$$
S=\sum\left[(\Delta Y)^{2}+(\Delta X)^{2}\right]
$$

since all the individual weights are equal. $\Delta Y$ is defined as $\left(Y_{o}-Y_{c}\right)$ and $\Delta X=\left(X_{o}-X_{c}\right)$.

The geometrical relation between $\Delta Y$ and $\Delta X$ that is assumed in Deming's method of solution is illustrated in figure 18 of ref. [47]. The relation for each point depends on the individual weights for that point.

If $w_{x}=w_{y}$, this condition requires that the line from the observed point, $\left(X, Y_{o}\right)$, to the calculated point, $\left(X_{c}, Y_{c}\right)$, be perpendicular to the calculated curve. 


\subsection{General Discussion of Method}

In many cases the least squares problem can be expressed as minimizing eq (17) subject to $M$ equations:

$$
F\left(X_{c, i}, Y_{c, i}\right)=0 \text {. }
$$

As an example consider a case in which three coefficients, $a, b$, and $c$, are to be fitted by least squares to the relation $Y=f(X, a, b, c)$. We take

$$
F(X, Y)=Y-f(X, a, b, c) .
$$

Using his geometrical relation between $\Delta Y$ and $\Delta X$, and using the Gaussian method of linearization of the problem by a truncated Taylor's Series expansion of the function, Deming derives a typical least squares solution "normal" equation as

$$
\begin{aligned}
\Delta a \sum_{i=1}^{M} W_{i} F_{a, i}^{2} & +\Delta b \sum_{i=1}^{M} W_{i} F_{a, i} F_{c, i} \\
& +\Delta c \sum_{i=1}^{M} W_{i} F_{a, i} F_{c, i}=\sum_{i=1}^{M} W_{i} F_{a, i} F_{o, i} .
\end{aligned}
$$

In this equation, the subscripts $a, b$, and $c$ designate the partial derivatives of $F$ with respect to the respective coefficients; $\Delta a=a_{1}-a_{c}$, the difference between the initial value, $a_{1}$, and the calculated or adjusted value, $a_{c} ; F_{o, i}=F^{3}\left(X_{0, i}, Y_{o, i}, a_{1}, b_{1}, c_{1}\right)$; and the weights are

$$
W_{i}=\left(F_{x, i}^{2} / w_{x, i}+F_{y, i}^{2} / w_{y, i}\right)^{-1} .
$$

$F_{x, i}$ and $F_{y, i}$ are the partial derivatives of $F$ with respect to $X$ and $Y$, respectively. Where a set of observations, $X_{o, i}$ and $Y_{o, i}$, can be assigned respective standard deviations $\sigma_{x, i}$ and $\sigma_{y, i}$, we take the weights as:

$$
w_{x, i}=1 / \sigma_{x, i}^{2} ; w_{y, i}=1 / \sigma_{y, i}^{2} .
$$

If variations in $X$ and $Y$ are independent, substitution of eq (22) in eq (21) yields

$$
W_{i}=1 / \sigma_{F, i}^{2}
$$

and hence the method is equivalent to statistical weighting of the individual sets of observations.

Using the Gaussian method, several iterations using the successively improved values of the coefficients may be used. The partial derivatives are usually evaluated using the observed values of $X$ and $Y$ in each iteration.

As pointed out by Deming, an advantage of the method is that the solution is unequivocal; i.e., the coefficients are independent of variations in the way of writing the equation. Thus a straight line can be written as either $Y=a+b X$ or $X=-a / b+$ $Y / b$ and correspondingly $F$ would be $(Y-a-b X)$ or $(X+a / b-Y / b)$. The values of $a$ and $b$ and the adjusted points will be the same to within higher powers of the residuals, $\Delta X$ and $\Delta Y$.
The least squares code used computes standard deviations of the fitted parameters based on the fit of the observed points to the calculated points. The code also permits computation of standard deviations of points calculated at interpolated or extrapolated points as well as at data points.

We are indebted to R. K. Zeigler and P. McWilliams for many discussions and for the development of the computer code.

\section{References*}

[1] S. G. Sydoriak, T. R. Roberts, and R. H. Sherman, Proc. 7 th Intern. Conf. Low Temperature Physics, ed. G. M. Graham and A. C. Hollis-Hallett (Univ. of Toronto Press, Toronto, 1961), ch. 30, p. 717.

[2] F. G. Brickwedde, H. van Dijk, M. Durieux, J. R. Clement, and J. K. Logan, J. Res. NBS 64A (Phys. \& Chem.), 1 (1960).

[3] D. F. Brewer, A. K. Sreedhar, H. C. Kramers, and J. G. Daunt, Phys. Rev. 115, 836 (1959).

[4] B. Weinstock, B. M. Abraham, and D. W. Osborne, Nuovo Cimento Suppl. 9, 310 (1958).

[5] B. M. Abraham, D. W. Osborne, and B. Weinstock, Phys. Rev. 80, 366 (1950).

[6] S. G. Sydoriak, T. R. Roberts, and R. H. Sherman, Paper II of this series.

[7] T. R. Roberts, R. H. Sherman, and S. G. Sydoriak, Paper III of this series.

[8] R. H. Sherman, S. G. Sydoriak, and T. R. Roberts, Paper IV of this series. See also Los Alamos Scientific Lab. Rept. LAMS 2701 (July 1962).

[9] S. G. Sydoriak and T. R. Roberts, Phys. Rev. 106, 175 (1957).

[10] T. R. Roberts, S. G. Sydoriak, and R. H. Sherman, Proc. 4th Symp. Temperature, Its Measurement and Control in Science and Industry, ed. C. M. Herzfeld (Reinhold Publ. Corp., New York, 1962), Vol. 3, pt. 1, p. 75 .

[11] W. E. Keller, Phys. Rev. 97, 1 (1955) ; 100, 1790 (1955).

[12] W. E. Keller, Phys. Rev. 98, 1571 (1955).

[13] F. E. Hoare and J. E. Zimmerman, Rev. Sci. Instr. 30, 184 (1959); R. T. Swim, Advances in Cryogenic Engineering, ed. K. D. Timmerhaus (Plenum Press, Inc., New York, 1960), Vol. 5, pp. 498-504.

[14] H. H. Plumb, Proc. 10th Intern. Congr. Refrigeration, Copenhagen, 1959, ed. M. Jul and A. M. S. Jul (Pergamon Press, Paris, 1960), Vol. 1, pp. 184-187.

[15] M. Durieux, Thermometry at Liquid Helium and Liquid Hydrogen Temperatures, Thesis, Leiden Univ. (16 Mar. 1960).

[16] F. G. Brickwedde, Report on the Conference Agreement on the Helium Vapor-Pressure Scale of Temperatures, Conf. Physique des Basses Temperatures, Paris, 2-8 Septembre 1955 , pp. 608-610.

[17] B. Bleaney and F. Simon, Trans. Faraday Soc. 35, 1205 (1939).

[18] B. Bleaney and R. A. Hull, Proc. Roy. Soc. (London) 178A, 74 (1941).

[19] J. de Boer and E. G. D. Cohen, Physica 1\%, 993 (1951).

[20] E. W. Becker and R. Misenta, Phys. Rev. 93, 244 (1954).

[21] E. W. Becker, R. Misenta, and F. Schmeissner, Z. Physik 13\%, 126 (1954).

[22] K. Mendelssohn and G. K. White, Proc. Phys. Soc. (London) A63, 1328 (1950).

[23] R. Bowers and K. Mendelssohn, Nature 163, 870 (1949); Proc. Phys. Soc. (London) A63, 1318 (1950).

*This list of references applies to papers I, II, III, and IV of this series. For completeness and convenience, it is reproduced in its entirety at the end of each
paper. 
[24] K. W. Taconis, Progress in Low Temperature Physics, ed. C. J. Gorter (North Holland Publ. Co., Amsterdam, The Netherlands, 1961), Vol. 3, p. 154.

[25] H. van Dijk and M. Durieux, Physica 24, 1 (1958)

[26] S. G. Sydoriak and H. S. Sommers, Jr., Rev. Sci. Instr. 22, 915 (1951).

[27] P. Kapitza, J. Phys. (U.S.S.R.) 4, 181 (1941).

[28] H. A. Fairbank and J. Wilks, Proc. Roy. Soc. (London) A231, 545 (1955).

[29] L. J. Challis, K. Dransfeld, and J. Wilks, Proc. Roy. Soc. (London) A260, 31 (1961)

[30] Kuang Wey-Yen, Zh. Experim. i Teor. Fiz. (U.S.S.R.) 42, 921 (1962); Soviet Phys. JETP (English Transl.) 15, $635(1962)$.

[31] I.M. Khalatnikov, Zh. Experim. i Teor. Fiz. (U.S.S.R.) 22, 687 (1952).

[32] S. G. Sydoriak and T. R. Roberts, Phys. Rev. 118, $901(1960)$.

[33] R. L. Mills, E.R. Grilly, and S. G. Sydoriak, Ann. Phys. 12, 41 (1961).

[34] W. Cawood and H. S. Patterson, Trans. Faraday Soc. 29, 522 (1933).

[35] J. Kistemaker, Leiden Commun. 268d (1944); Physica 11, 277 (1944-1946); B. E. Blaisdell, J. Math. Phys. 19, $186(1940)$.

[36] W. G. Brombacher, D. P. Johnson, and J. L. Cross, Mercury Barometers and Manometers, NBS Mono. 8 (U.S. Govt. Printing Office, Washington, 1960).

[37] T. R. Roberts and S. G. Sydoriak, Phys. Rev. 102, 304 (1956).

[38] B. N. Esel'son and N. G. Berezniak, Zh. Experim. i Teor. Fiz. (U.S.S.R.) 30, 628 (1956); Soviet Phys. JETP (English Transl.) 3, 568 (1956).

[39] S. G. Sydoriak, E. R. Grilly, and E. F. Hammel, Phys. Rev. 75, 303 (1949).

[40] V. P. Peshkov, Zh. Experim. i Teor. Fiz. (U.S.S.R.) 33, 833 (1957) ; Soviet Phys. JETP (English Transl.) 4, 645 (1958).

[41] H. van Dijk and D. Shoenberg, Nature 164, 151 (1949).

[42] T. C. Chen and F. London, Phys. Rev. 89, 1038 (1953).

[43] W. E. Keller, Nature 178, 883 (1956); J. R. Clement, Low Temperature Physics and Chemistry (Univ. of
Wisconsin Press, Madison, 1958), p. 187 (Proc. 5th Intern. Conf. Low Temperature Physics and Chemistry, Madison, Wis., 1957).

[44] L. Goldstein, Phys. Rev. 96, 1455 (1954); Phys. Rev. 102, 1205 (1956).

[45] R. H. Sherman, T. R. Roberts, and S. G. Sydoriak, Supplement au Bulletin de l'Institut International du Froid, Annexe 1961-5, p. 125 (Proc. Meeting of Commission I of the International Institute of Refrigeration, London, 1961).

[46] S. G. Sydoriak and R. H. Sherman, Paper I of this series.

[47] W. E. Deming, Statistical Adjustment of Data (John Wiley \& Sons, New York, 1943).

[48] T. R. Roberts, S. G. Sydoriak, and R. H. Sherman, see ref. [45], p. 115.

[49] E. R. Grilly and E. F. Hammel, Progress in Low Temperature Physics III (1961), pp. 113-152.

[50] E. C. Kerr and R. D. Taylor, Proc. 7th Intern. Conf. Low Temperature Physics, ch. 24, pp. 605-608, ed. G. M. Graham and A. C. Hollis-Hallett (Univ. of Toronto Press, Toronto, 1961).
[51] R. H. Sherman and F. J. Edeskuty, Ann. Phys. 9, 522 (1960).

[52] T. R. Roberts, R. H. Sherman, S. G. Sydoriak, and F. G. Brickwedde, Progress in Low Temperature Physics IV, ch. 10 (North Holland Publ. Co., Amsterdam, The Netherlands, 1964), p. 480.

[53] A. M. Mood, Introduction to the Theory of Statistics, p. 299 (McGraw-Hill, New York, N.Y., 1950).

[54] M. Durieux, Procès-Verbaux du Comité Consultatif de Thermométrie auprès du Comité International des Poids et Mesures, 6e Session, 1962 (GauthierVillars, Paris, France, 1964), p. 190.

[55] D. W. Osborne, private communication.

[56] R. Berman and C. F. Mate, Phil. Mag. 3, 461 (1958).

[57] H. van Dijk, Progr. Cryog. 2, p. 125 (Academic Press, Inc., New York, N.Y., 1962).

[58] G. Cataland and H. H. Plumb, Proc. 8th Intern. Conf. Low Temperature Physics, London, Sept. 16-22, 1962, ed. R. O. Davies (Butterworths, Washington, D.C., 1963), pp. 439-40

[59] E. C. Kerr, Phys. Rev. 96, 551 (1954).

[60] E. C. Kerr and R. D. Taylor, Ann. Phys. 20, 450 (1962).

[61] A. C. Anderson, G. L. Salinger, W. A. Steyert, and J. C. Wheatley, Phys. Rev. Letters 6, 331 (1961); A. C. Anderson, W. Reese, and J. C. Wheatley, Phys. Rev. 130, 495 (1963).

[62] M. Strongin, G. O. Zimmerman, and H. A. Fairbank, Phys. Rev. 128, 1983 (1962).

[63] B. M. Abraham, D. W. Osborne, and B. Weinstock, Phys. Rev. 98, 551 (1955).

[64] G. R. Grove and W. J. Haubach, Jr.; see ref. [58], p. 441. For further information, write Gaseous Isotope Sales, Montsanto Research Corporation, Mound Laboratory, Miamisburg, Ohio.

[65] D. O. Edwards and J. G. Daunt, Phys. Rev. 124, 640 (1961).

[66] S. G. Sydoriak, T. R. Roberts, and R. H. Sherman; see ref. [58], pp. $437-8$.

[67] J. A. Hall, Sixième Rapport du Comité Consultatif de Thermométrie au Comité International des Poids et Mesures; see ref. [54].

[68] H. F. Stimson, NBS Tech. News Bull. 4\%, No. 2, 30 (Feb. 1963); Nature 19\%, 1055 (1963).

[69] F. G. Brickwedde, Phys. Today 16, 24 (1963).

[70] S. Weber, Commun. Kamerlingh Onnes Lab. Univ. Leiden Suppl. $\boldsymbol{g 1 b}$ (1932), 264b and 264d (1936).

[71] S. Weber and G. Schmidt, Commun. Kamerlingh Onnes Lab. Univ. Leiden 264c (1936).

[72] C. E. Chase, E. Maxwell, and W. M. Whitney, Physica 26, 160 (1960); C. E. Chase, E. Maxwell, and W. E. Millett, Physica \%\%, 1129 (1961).

[73] R. H. Moore and R. K. Zeigler, Trans. Am. Nuclear Soc. 1, 128-9 (1958); The Solution of the General Least Squares Problem with Special Reference to High-Speed Computers, Los Alamos Scientific Lab. Rept. LA-2367 (Mar. 4, 1960).

[74] T. R. Roberts and B. K. Swartz, Proc. 2 d Symp. Liquid and Solid Helium Three, ed. J. G. Daunt (Ohio State Univ. Press, Columbus, 1960), p. 163.

(Paper 68A6-303) 